\title{
Investigation of oxidative stress in patients with alopecia areata by measuring the levels of malondialdehyde and ceruloplasmin in the blood
}

\author{
Anna Cwynar ${ }^{1}$, Dorota Olszewska-Słonina ${ }^{1}$, Rafał Czajkowski², Barbara Zegarska ${ }^{3}$, Agnieszka Białecka², \\ Kaja Męcińska-Jundziłt², Elżbieta Piskorska ${ }^{1}$, Magdalena Lampka ${ }^{1}$
}

${ }^{1}$ Department of Pathobiochemistry and Clinical Chemistry, Collegium Medicum in Bydgoszcz, Nicolaus Copernicus University in Torun, Poland

${ }^{2}$ Department of Dermatology, Sexually Transmitted Disorders and Immunodermatology, Collegium Medicum in Bydgoszcz,

Nicolaus Copernicus University in Torun, Poland

${ }^{3}$ Department of Cosmetology and Aesthetic Dermatology, Collegium Medicum in Bydgoszcz, Nicolaus Copernicus University in Torun, Poland

Adv Dermatol Allergol 2018; XXXV (6): 572-576

DOI: https://doi.org/10.5114/pdia.2017.68047

\begin{abstract}
Introduction: Alopecia areata (AA) is a chronic, inflammatory and autoimmune disease, presenting with nonscarring hair loss. Although the precise etiopathogenesis of AA remains unknown, oxidative stress is thought to play a role.

Aim: To investigate the role of oxidative stress in AA by measuring the levels of plasma and erythrocyte malondialdehyde (MDA) and the ceruloplasmin (CER) in serum.

Material and methods: The study included 24 AA patients and a control group consisting of 24 age- and sexmatched healthy volunteers. The levels of MDA and CER were measured and compared between groups.

Results: Plasma MDA levels were significantly higher $(p<0.05)$ in patients with AA compared with controls. No significant difference was observed in MDA erythrocyte levels $(p=0.990)$ between the study group and the control group. Ceruloplasmin level was higher in the AA group, but this increase was not statistically significant $(p=0.156)$. Conclusions: Patients with AA displayed significant plasma MDA levels, which could lead to damage in erythrocytes exposed to high concentrations of free radicals. These results demonstrate the presence of an imbalance in the oxidant-antioxidant system and support the concept of a possible role of oxidative stress in AA etiopathogenesis.
\end{abstract}

Key words: alopecia areata, ceruloplasmin, malondialdehyde, oxidative stress.

\section{Introduction}

Alopecia areata (AA) is a disease of the scalp and the whole body of not completely known etiopathogenesis. It is quite common and accounts for $0.7 \%$ to $3.9 \%$ of diagnoses in patients presenting to dermatology clinics. The disease incidence is estimated at $1-2 \%$ of the total population. The course may be very different and individual for each patient [1].

In the general population men and women develop the disease equally often. The onset of the disease occurs usually in childhood or in young age, but it may appear at any time of life. The earlier the symptoms appear, the worse the course of AA is and the more difficult it is to treat [1].
Although the etiopathogenesis of AA remains not fully explained, it is thought that the disease is caused by a sudden transition of hair from the anagen phase into the phase of early catagen. It has not been explained yet what factors are responsible for initiating this process. There are many hypotheses explaining the etiopathogenesis of $A A[2,3]$.

The role of the immune system and the autoimmune determination of this disease are stressed in the pathogenesis of alopecia in the first place. The basis for such assumptions derive from observations concerning coexistence of AA with other autoimmune diseases (thyroiditis, Hashimoto's thyroiditis, albinism, systemic

Address for correspondence: Anna Cwynar, Department of Pathobiochemistry and Clinical Chemistry, Collegium Medicum, Nicolaus Copernicus University, 9 M. Curie-Skłodowskiej St, 85-094 Bydgoszcz, Poland, phone: +48 793414 790,

e-mail: anna.cwynar@vp.pl

Received: 15.03.2017, accepted: 13.04.2017. 
lupus erythematosus, Addison's disease, type 1 diabetes, myasthenia gravis, rheumatoid arthritis, Crohn's disease) and good response to treatment with steroids and local immunomodulators [3, 4].

Lymphocytic infiltrates, which damage the root of anagen hair, seem to play the key role in AA pathogenesis. The dominant role is played by $T$ lymphocytes. Infiltrations are observed mostly around the hair follicles in the anagen phase, which accelerates their transition into the catagen phase. Also disorders of keratinocyte proliferation occur, which prevents the regrowth of hair [5].

The studies of recent years indicate possible participation of oxidative stress in the course of AA. It has been shown that a higher plasma concentration of malondialdehyde (MDA) occurs in patients with AA than in the group of healthy subjects. Malondialdehyde, as an indirect indicator of oxidative stress, informs about the degree of damage to the plasma membranes as a result of action of free radicals $[6,7]$.

Red blood cells (RBCs) are among the first cells to be affected by free radicals and oxidative damage due to the high content of unsaturated fatty acid chains in the lipid bilayer containing significant oxygen concentration and hemoglobin as well, a major promoter of the oxidative process. In the laboratory, RBCs are frequently used as an in vitro model for the study of oxidative stress $[8,9]$. Obtained results indicate disturbances of oxidative balance manifested by an increase in products of lipid peroxidation in AA subjects.

Ceruloplasmin (CER) belongs to the group of positive acute phase proteins, whose concentration increases by about $50 \%$ in plasma after the action of a damaging factor. Due to the kinetics of changes CER is numbered among the second line proteins whose plasma concentration increases $24-28 \mathrm{~h}$ after the moment of activation of the stimulus initiating the acute-phase reaction. At the same time ceruloplasmin takes part in defensive mechanisms in oxidative stress. It belongs to preventive antioxidants, and its ability to bind transition metal ions prevents formation of the superoxide anion $\left(\mathrm{O}_{2}^{--}\right)$. It catalyses the reaction of oxidation of ferrous ions $\left(\mathrm{Fe}^{2+}\right)$ to ferric $\left(\mathrm{Fe}^{3+}\right)$, which determines binding iron to transferrin and ferritin. Ceruloplasmin has the ability to oxidize substrates in reactions which are accompanied by a fourelectron reduction of an oxygen molecule to two molecules of water. It also acts as an oxidase towards a wide group of organic substrate and performs many catalytic functions, showing e.g. the activity of glutathione peroxidase. Currently it is believed that CER is responsible for about $80 \%$ of plasma oxidative properties [10-12].

\section{Aim}

This study aims to investigate the role of oxidative stress in cases of AA and in healthy controls by measur- ing the levels of plasma and erythrocyte malondialdehyde and the level of ceruloplasmin in serum.

\section{Material and methods}

This study was conducted jointly in the Department of Pathobiochemistry and Clinical Chemistry, Clinic of Dermatology, Sexually Transmitted Diseases and Immunodermatology NCU, Antoni Jurasz University Hospital No. 1 in Bydgoszcz after institutional ethical clearance.

The study included 24 AA patients (16 female/ 8 male, mean age: $34.2 \pm 9.1)$ and the control group consisting of 24 age- and sex-matched healthy volunteers (15 female/ 9 male, mean age: $33.2 \pm 16.6$ ). There was no significant difference in age or body mass index (BMI) between groups.

Clinical diagnosis of the disease was made by a dermatologist. However, it needs to be pointed out that AA typically coexists with other autoimmune diseases such as thyroid disorders and other skin disorders with autoimmune etiology, which can also influence the results.

The controls had no history of any topical or systemic drug therapy including antifungals, steroids, anticonvulsants or anti-inflammatory drugs, and none of them had any other coexistent systemic or cutaneous diseases.

The research was approved by the Local Bioethics Committee (KB549/2013) and all study participants signed an informed consent form.

\section{Sample collection}

Samples for fasting blood tests were collected from an ante-cubital vein under aseptic conditions, during routine checks. All samples were kept in dry and sterile testtubes (Grainer Bio-one, Kremsmünster Austria). Blood sampling in the control group was performed once during routine medical examinations at the time of the study.

\section{Biochemical assays}

\section{Preparation of erythrocyte hemolysate and plasma}

Sample assays and serum preparation were completed in the university laboratory within $2 \mathrm{~h}$ after they were collected. Plasma was obtained by centrifuging venous blood collected into tubes containing $\mathrm{K}_{3}$ EDTA (Vacuette) at $4000 \mathrm{~g}$ for $10 \mathrm{~min}$ at $+4^{\circ} \mathrm{C}$. After removing plasma the blood cells were washed three times in phosphate-buffered saline (PBS) in a ratio of $1: 3: 1$ and centrifuged after each wash. Packed red blood cells were diluted $1: 1$ with PBS solution. The hemoglobin concentration in the hemolysates was assayed with the colorimetric standard method using Drabkin's reagent and expressed as g/dl.

\section{Measurement of MDA levels}

Concentration of thiobarbituric acid reactive substances (TBARS) - MDA level was determined according 
to Buege and Aust in Esterbauer and Cheeseman's later modification.

\section{Determination of MDA level in erythrocytes}

This method is based on the reaction with thiobarbituric acid (TBA) in an acidic $\mathrm{pH}$ and at $90-100^{\circ} \mathrm{C}$. In the test reaction, MDA or MDA-like substances (formed as secondary products during lipid peroxidation) and TBA react with production of a pink pigment having an absorption maximum of $532 \mathrm{~nm}$. The specimens were joined with butylated hydroxytoluene $(\mathrm{BHT})$ and trichloroacetic acid (TCA), then incubated at room temperature for $10 \mathrm{~min}$ and centrifuged (4000 g, $10 \mathrm{~min}$ ). The supernatants were reacted with a mixture of TBA and TCA in a boiling water bath for $20 \mathrm{~min}$. After cooling, the absorbance was read at $532 \mathrm{~nm}$.

\section{Determination of MDA level in blood plasma}

The samples were mixed with a mixture of TBA and TCA in $\mathrm{HCl}$ to precipitate protein. The reaction was performed at $\mathrm{pH} 2-3$ at $90^{\circ} \mathrm{C}$ for $20 \mathrm{~min}$. The precipitate was pelleted by centrifugation at $4000 \mathrm{~g}$, room temperature for 15 min. Absorption of supernatants was read at a wavelength of $532 \mathrm{~nm}$.

The majority of TBARS are malondialdehydes; thus the concentration of MDA in blood plasma was expressed as $\mathrm{nmol} \mathrm{MDA} / \mathrm{ml}$. The results were calculated using an extinction coefficient for MDA of $1.56 \times 10^{5} / \mathrm{M} / \mathrm{cm}$ (molar absorptivity - a parameter defining how strongly a substance absorbs light at a given wavelength, per molar concentration). The concentration of MDA in erythrocytes was expressed as nmol MDA/g Hb.

\section{Measurement of CER levels}

Determination of ceruloplasmin activity was performed using the automatic biochemical analyzer COBAS INTEGRA 400 with the immunoturbidimetric method. Material for the study was serum. The concentration of CER in serum was expressed as mg CER/dl serum.

\section{Chemicals}

TBA, TCA, adrenaline and hydrogen peroxide were purchased from Fluka (Sigma-Alrich sp. z o.o., Poland).
BHT was from Aldrich (Sigma-Aldrich sp. z o.o., Poland). Other reagents were of analytical grade.

\section{Statistical analysis}

Statistical analysis was carried out using the PQStat v. 1.6.2 for Windows statistical software. KolmogorovSmirnov test was applied for the compatibility estimation of the assessed parameters distribution with normal distribution. All results were expressed as mean \pm SD. The unpaired Student's t-test was used to compare the mean values between the groups. The level of statistical significance was set at $p<0.05$.

Pearson's correlation coefficient, as a measure of the strength of linear dependence between two variables, was used to assess the relationship between parameters. A two-tailed $p$-value of $<0.05$ was considered statistically significant.

\section{Results}

The present study aimed to evaluate the levels of oxidative stress indicators in the blood of patients with alopecia. Plasma MDA levels were significantly increased $(p=0.021)$ in patients with AA compared with controls. However, no significant differences were observed in MDA erythrocyte levels ( $p=0.990)$ between the study group and the healthy volunteers. Ceruloplasmin level was higher in the study group, but this increase was not statistically significant $(p=0.156)$. There was a positive correlation between plasma MDA levels and CER in the control group $(r=0.567, p=0.003)$. The mean results and statistical values are presented in Table 1.

\section{Discussion}

Alopecia areata is considered to be an autoimmune disease [13]. Autoimmune diseases are caused by complex conditions involving both genetic and environmental factors. It is believed that excessive oxidative stress may play an essential role in the pathogenesis of autoimmune diseases by intensification of inflammation, induction of cell apoptosis and reduction of immune tolerance [14].

Many studies have reported the involvement of oxidative stress in $\mathrm{AA}[10,11,15]$. For this reason, the levels

Table 1. Values of MDA and CER in peripheral blood of alopecia patients and healthy subjects

\begin{tabular}{lccc}
\hline Parameter & $\begin{array}{c}\text { AA patients } \\
(\boldsymbol{N}=24)\end{array}$ & $\begin{array}{c}\text { Healthy subjects } \\
(\boldsymbol{N}=24)\end{array}$ & $P$-value \\
\hline MDAe $[\mathrm{nmol} / \mathrm{g} \mathrm{Hb}]$ & $21.258 \pm 8.075$ & $21.289 \pm 9.329$ & 0.990 \\
\hline MDA [nmol/ml plasma] & $0.486 \pm 0.091$ & $0.429 \pm 0.072$ & 0.021 \\
\hline CER $[\mathrm{mg} / \mathrm{dl}$ serum] & $25.050 \pm 7.088$ & $22.649 \pm 4.039$ & 0.156 \\
\hline
\end{tabular}

MDAe - malondialdehyde concentration in erythrocytes, MDA - malondialdehyde concentration in blood plasma, CER - ceruloplasmin in blood serum, $p$-statistical significance level. 
of MDA for the evaluation of oxidative stress and CER for the evaluation of antioxidant defense system efficiency in alopecia patients were investigated.

Malondialdehyde is one of the final products of polyunsaturated fatty acid peroxidation located on the cell membranes and it proceeds further with the radical chain reaction. An increase in free radicals causes overproduction of MDA $[14,16]$. Malondialdehyde is one of the most popular and reliable markers for determination of oxidative stress in clinical situations. It has been proved that as compared to the control group, a higher plasma MDA concentration occurs in patients with AA than in the group of healthy volunteers. Malondialdehyde, as an indirect indicator of oxidative stress, informs about the degree of plasma membrane damage as a result of the action of free radicals. Malondialdehyde is widely used as a marker for measuring lipid peroxidation levels to evaluate the oxidative damage of erythrocytes. Obtained results indicate disturbance of oxidative balance, manifested by an increase in products of lipid peroxidation in AA subjects [17].

Red blood cells are the first cells in the body to be exposed to stressful stimuli. Oxidative stress plays a significant role in damaging the RBC membrane and impairing its deformability. Due to this fact, RBCs are frequently used as an in vitro model for evaluation of the antioxidant properties of different factors and also for assessment of oxidative stress during human health and disease $[8,9,18]$.

Consequently, the significantly higher levels of serum MDA obtained in this study support previous findings and indicate that lipid peroxidation may have a role in the pathogenesis of AA.

Ceruloplasmin belongs to the group of acute phase proteins and constitutes a good diagnostic indicator in conditions of system homeostasis disorders. It is the main copper oxidase present in blood plasma. At the same time it affects the anti-oxidative abilities of the organism and provides protection against free radical reactions. Its presence determines the enzymatic activity of superoxide dismutase (Cu, ZnSOD), which is the key enzyme of the antioxidant barrier of the body. Ceruloplasmin acts as a peroxidase towards a wide range of organic substrates. It also performs many catalytic functions, showing among others the activity of glutathione peroxidase $[12,19]$.

This study shows a higher ceruloplasmin concentration in blood serum of AA subjects as compared with the control group. However, the results do not show statistically significant differences, which may be due to the limited sample size. The increase of CER concentration in patients with AA indicates possible presence of disturbance in the oxidative-antioxidant balance of the organism. Moreover, a positive correlation between plasma MDA and CER concentration was observed, but only in the group of healthy people. The lack of a similar relation- ship within the study group may be further evidence of the disruption of oxidative-antioxidative balance and the presence of oxidative stress in AA pathogenesis.

\section{Conclusions}

Studying the etiopathogenesis of AA still remains a challenge, and therapy of this disease is a serious problem in dermatological practice. In spite of intensive research work, there are still no effective treatment methods. Our results demonstrate the presence of an imbalance in the oxidant-antioxidant system and support the concept of possible existence of oxidative stress in AA. Oxidative balance disorder accompanying this disease may be a potential target for new therapies.

\section{Acknowledgments}

The authors thank the Department of Medical Biology (Nicolaus Copernicus University in Torun) for technical support during the preparation of this manuscript.

\section{Conflict of interest}

The authors declare no conflict of interest.

\section{References}

1. Joss-Wichman E, Broniarczyk-Dyła G. Współczesne poglądy na etiopatogenezę łysienia plackowatego. Post Derm Alergol 2005; 22: 189-98.

2. Łuczak M, Łuczak T, Cieścińska C, et al. Leczenie ogólne tysienia plackowatego. Przegl Dermatol 2013; 100: 53-8.

3. Sudnik W. Rola selekty E, L i P w patomechanizmie tysienia plackowatego. Doctor thesis, Medical University, Poznan, 2012.

4. Thomas EA, Kadyan RS. Alopecia areata and autoimmunity: a clinical study. Indian J Dermatol 2008; 53: 70-4.

5. Van Baar HM, Perret CM, Van Vlijmen IM, et al. Abnormal expression of Ki-67 antigen in hair follicle of alopecia areata. Acta Derm Venereol 1992; 72: 1161-5.

6. Abdel Fattah NS, Ebrahim AA, El Okda ES. Lipid peroxidation/antioxidant activity in patients with alopecia areata. J Eur Acad Dermatol Venereol 2011; 25: 403-8.

7. Akar A, Arca E, Erbil H, et al. Antioxidant enzymes and lipid peroxidation in the scalp of patients with alopecia areata. J Dermatol Sci 2002; 29: 85-90.

8. Hale JP, Winlove P, Petrov PG. Effect of hydroperoxides on red blood cell membrane mechanical properties. Biophys J 2011; 101: 1921-9.

9. Pandey KB, Rizvi SI. Biomarkers of oxidative stress in red blood cells. Biomed Pap Med Fac Univ Palacky Olomouc Czech Repub 2011; 155: 131-6.

10. Wierzbicka D, Gromadzka G. Ceruloplazmina, hefajstyna i cyklopen: trzy multimiedziowe oksydazy uczestniczące w metabolizmie żelaza u człowieka. Post Hig Med Dośw 2014; 68: 912-24.

11. Borzęcki B. Druga twarz tlenu - wolne rodniki w przyrodzie. PWN, Warsaw 2012. 
12. Augustyniak A, Skrzydlewska E. Zdolności antyoksydacyjne w starzejącym się organizmie. Post Hig Med Dośw 2004; 58: 194-201.

13. Esterbauer H, Cheeseman KH. Determination of aldehydic lipid peroxidation products: malonaldehyde and 4-hydroxynonenal. Method Enzymol 1990; 186: 407-21.

14. Karolkiewicz J. Effects of oxidative stress and free-radical mediated damage on cell structure and function - connection to aging processes. Gerontol Pol 2011; 2: 57-69.

15. Thomas EA, Kadyan RS. Alopecia areata and autoimmunity: a clinical study. Indian J Dermatol 2008; 53: 70-4.

16. Gawet S, Wardas M, Niedworok E, et al. Malondialdehyde (MDA) as a lipid peroxidation marker. Wiad Lek 2004; 57 : 453-5.

17. Prie BE, Voiculescu VM, lonescu-Bozdog OB, et al. Oxidative stress and alopecia areata. J Med Life 2015; 8: 43-6.

18. Mohanty JG, Nagababu E, Rifkind JM. Red blood cell oxidative stress impairs oxygen delivery and induces red blood cell aging. Front Physiol 2014; 5: 84.

19. Buege SC, Aust SD. Microsomal lipid peroxidation. Methods Enzymol 1987; 51: 302-10. 